\title{
Dimensiones del Bulbo Húmedo en Riego Localizado 1
}

\section{Elsa S. Sepúlveda y Fedro S. Zazueta²}

Para calcular el número de emisores por plantas requeridos por un sistema localizado, es necesario calcular las dimensiones del bulbo húmedo generado por el sistema. Para garantizar el abastecimiento necesario de agua y nutrientes a la planta se recomienda que una fracción suficientemente grande de la zona radicular sea humedecida.

Este programa calcula las dimensiones del bulbo húmedo resultante de una fuente puntual en suelos arenosos. Nótese que el método no ha sido comprobado en otros tipos de suelos. Además, el método se aplica solo a suelos profundos, uniformes y homogeneos.

\section{Ecuación Empírica}

Existen varios métodos que permiten calcular en forma aproximada las dimensiones del bulbo húmedo. Estos incluyen reportes de pruebas de campo (Golberg et. al, 1976), y las ecuaciones empíricas presentadas por Schwartzmass y Sur (1985), y Zazueta (1992). Otras formas de presentar estos resultados son las tablas presentadas por Keller y Bliesner (1990).
Este programa implementa la ecuación desarrollada por Zazueta (1992):

$$
D=0.01\left(\frac{q r}{I}\right)^{1 / 3}
$$

Donde:

$$
\mathrm{D} \text { = diámetro aproximado del bulbo húmedo }
$$

(m),

$$
\begin{aligned}
& \mathrm{q}=\text { descarga del emisor }(\mathrm{l} / \mathrm{hr}), \\
& \mathrm{r}=\text { profundidad de la raíz }(\mathrm{m}), \mathrm{y} \\
& \mathrm{I}=\text { tasa de infiltración básica }(\mathrm{m} / \mathrm{s}) .
\end{aligned}
$$

\section{Descarga e Instalación del Software}

Este software puede ser descargado de http://fsz.ifas.ufl.edu. el archivo es un archivo comprimido en el formato Zip. Extraiga los archivos y ejecute el programa de instalación (setup.exe). Siga las instrucciones en la pantalla para completar la instalación.

1. Este documento con la identificación ABE351S, es uno de una serie de publicaciones del Departamento de Ingeniería Agrícola y Biológica del Servicio de Extensión Cooperativo de la Florida, del Instituto de Alimentos y Ciencias Agrícolas, universidad de la Florida. Publicado por primera vez en Marzo de 2004. Por favor, visite la dirección en la Red EDIS en <http://edis.ifas.ufl.edu>.

2. Académico Visitante de la Universidad de Concepción, Chile, en el Departamento de Ingeniería Agrícola y Biológica; Director y Profesor, Oficina de Tecnología Académica, Universidad de Florida, Gainesville, FL 32611 


\section{Ejemplo de Ejecución}

La Figura 1 muestra a un Pocket PC cuando el programa es ejecutado. Ingrese los datos correspondientes a cada campo (descarga del emisor, profundidad de la raiz y tasa de infiltración básica) y oprima el botón calcula para obtener el resultado.

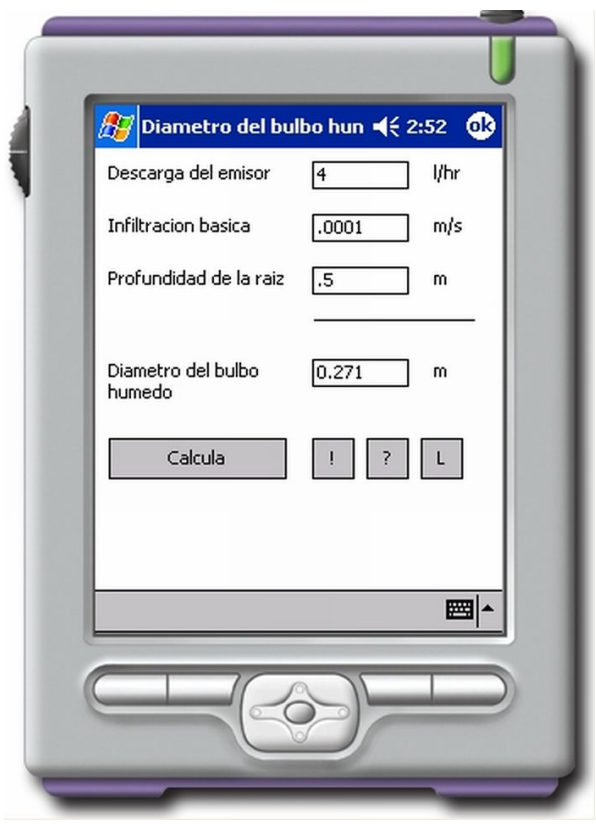

Figura 1: Interface del programa.

\section{Referencias}

Goldberg, D., B. Gornat, and D. Rimon. Drip Irrigation. Drip Irrig. SCi. Pubs. Kfar Shmaryhu, Israel. 1976.

Keller, J. and R.D. Bliesner. Sprinkle and Trickle Irrigation. Van Nostrand Reinhold, New York. 1990. $652 \mathrm{p}$.

Schwartzmass, N., and B. Zur. 1985. Emitter Spacing and geometry of wetted soil volume. Journal of Irrigation and Drainage Engineering, ASCE.

112(3):242-253.

Zazueta, F.S. Microirrigación. ICFA

International, Guadalajara, México, 1992. 212 p. 